\title{
TRANSPORTATION BARRIERS TO ACCESS HEALTH CARE FOR SURGICAL CONDITIONS IN MALAWI a cross sectional nationwide household survey
}

Carlos Varela ${ }^{1,2,3^{*}}$ D, Sven Young ${ }^{1,2,4}$, Nyengo Mkandawire ${ }^{8}$, Reinou S. Groen ${ }^{6,7}$, Leonard Banza ${ }^{1,2,3}$ and Asgaut Viste ${ }^{3,5}$

\begin{abstract}
Background: It is estimated that nearly five billion people worldwide do not have access to safe surgery. This access gap disproportionately affects low-and middle-income countries (LMICs). One of the barriers to healthcare in LMICs is access to transport to a healthcare facility. Both availability and affordability of transport can be issues delaying access to health care. This study aimed to describe the main transportation factors affecting access and delay in reaching a facility for health care in Malawi.

Methods: This was a multi-stage, clustered, probability sampling with systematic sampling of households for transportation access to general health and surgical care. Malawi has an estimated population of nearly 18 million people, with a total of 48,233 registered settlements spread over 28 administrative districts. 55 settlements per district were randomly selected for data collection, and 2-4 households were selected, depending on the size. Two persons per household were interviewed.

The Surgeons Overseas Assessment of Surgical need (SOSAS) tool was used by trained personnel to collect data during the months of July and August 2016.

Analysis of data from 1479 households and 2958 interviewees was by univariate and multivariate methods.

Results: Analysis showed that $90.1 \%$ were rural inhabitants, and $40 \%$ were farmers. No formal employment was reported for $24.9 \%$ persons. Animal drawn carts prevailed as the most common mode of transport from home to the primary health facility - normally a health centre. Travel to secondary and tertiary level health facilities was mostly by public transport, 31.5 and $43.4 \%$ respectively. Median travel time from home to a health centre was $1 \mathrm{~h}$, and $2.5 \mathrm{~h}$ to a central hospital. Thirty nine percent of male and 59\% of female head of households reported lack financial resources to go to a hospital.

Conclusion: In Malawi, lack of suitable transport, finances and prolonged travel time to a health care centre, all pose barriers to timely access of health care. Improving the availability of transport between rural health centres and district hospitals, and between the district and central hospitals, could help overcome the transportation barriers to health care.
\end{abstract}

Keywords: Transport, Barriers, Health, Access, SOSAS, Survey

\footnotetext{
* Correspondence: cegomesv@gmail.com

${ }^{1}$ Department of Surgery Kamuzu Central Hospital, Lilongwe, Malawi

${ }^{2}$ University of Malawi, College of Medicine, Lilongwe, Malawi

Full list of author information is available at the end of the article
}

(c) The Author(s). 2019 Open Access This article is distributed under the terms of the Creative Commons Attribution 4.0 International License (http://creativecommons.org/licenses/by/4.0/), which permits unrestricted use, distribution, and reproduction in any medium, provided you give appropriate credit to the original author(s) and the source, provide a link to the Creative Commons license, and indicate if changes were made. The Creative Commons Public Domain Dedication waiver (http://creativecommons.org/publicdomain/zero/1.0/) applies to the data made available in this article, unless otherwise stated. 


\section{Background}

Over the last decade the burden of disease treatable by surgery has been assumed to be arround 11\%, based on an expert opinion estimate by Debas et al. in 2006 (Debas H, Gosselin R. et al. 2nd Washington World Bank; 2006 p.1245-1259) Recent estimates indicate that this figure is likely to be much higher. Estimates of the global burden of surgical disease based on a multinational survey from the provider perspective indicate that $32.9 \%$ of deaths and $28.1 \%$ of disability-adjusted life years (DALYs) could be lost due to surgically treatable conditions (Shrime et al) [1].

In rural sub-Saharan Africa there is limited information available of morbidity and mortality due to surgical diseases. In East African rural communities it has been estimated that mortality from injury related surgical conditions and cancer is $100 / 100,000$ and $60 / 100,000$ population per year respectively [2]. Taira et al. [3] concluded that there is very limited access and availability of surgical care across the developing world. A study in Tanzania showed that more than $90 \%$ of the population in the North of the country does not have access to orthopaedic surgical care [4].

The Lancet commission on Global Surgery estimated that 5 billion people do not have access to safe surgery [1], and the access is inequitably distributed. Lin et al. [5] showed that $96 \%$ of their study patients experienced a barrier to surgical care. $73 \%$ reported that this was due to costs, $8.2 \%$ reported that it was due to lack of a provider. They concluded that barriers to surgery were predicted by patients' wealth and home location in The Republic of Congo [5].

Malawi, a sub-Saharan low income country (LIC), is no exception from this situation. Hospitals in rural sub-Saharan Africa, including Malawi, have not met the surgical needs of the population they serve, which has resulted in significant morbidity and mortality [6].

Though it has been shown that the health work force is severely inadequate at different levels of health provision in Malawi [7], there are multiple other barriers faced by rural communities to access health care for different medical and surgical conditions. Some of the many delayed presentations of disease seen in medical practice in low income settings have been shown to be due to the cost of transportation and time taken to reach the health facility [8], but so far there has been no study on factors posing a barrier to surgical care in Malawi.

The Malawi health care system has two main service providers: Non-governmental district facilities under Christian Health Association of Malawi (CHAM) and governmental facilities. CHAM is a network of church-owned health facilities, hospitals and training colleges run by faith based organisations with financial support from Malawi Government. CHAM has 175 health facilities and provides $37 \%$ of Malawi's healthcare services. Unlike the free services provided by the government facilities, CHAM offers its services at a cost. The government health structure is designed in a three-tiered network of medical facilities. The primary tier is a network of rural health facilities, referred to as health centres, which are run by medical assistants and nurses, with no doctors. Further, medical supplies are often scarce. The second tier is the district hospital which caters for the critical medical case which cannot be handled in a health centre. These facilities are located centrally in each of Malawi's 28 districts. District hospitals can handle some surgical cases if doctors or clinical officers with some surgical training are available, but they have no specialist surgeons to provide advanced surgical care. The top tier is the tertiary central hospitals which have more advanced equipment, medical supplies and medical personnel including different specialised doctors. The tertiary hospitals are only located in the four main urban areas. While CHAM provides $37 \%$ of health care delivery in Malawi, the government health facilities are responsible for 60 , and $3 \%$ is served by private institutions and organisations [9].

People living in rural Malawi face major challenges due to long distances between the community and the nearest health facility, be it a health centre, district hospital or central hospital. $50 \%$ of Malawians live within 5 $\mathrm{km}$ from a health facility $[9,10]$. Terrain and lack of road infrastructure can be a challenge in itself in some areas. Some areas are accessible by push bicycle, bicycle ambulances, and motor cycles only, others by ox-carts, lorries and motor cars. The transportation means are challenging, and in some areas the most used mode of transport is the bicycle ambulance for transferring especially maternity patients from rural health facility to district hospitals [11]. Occasionally transportation from primary health facility to secondary or tertiary health facility is provided by public hospital ambulances. Most of the roads in rural Malawi are dirt roads and many do not have bridges, making use in the rainy season even more of a challenge.

Even when the roads are passable by different means of transport, the distance from the community to the health facility has in itself been shown to influence health seeking behaviour in Malawi resulting in a gap in the accessibility of the public health service [12].

Transportation cost and cultural factors have also been shown to influence access to health care $[11,13]$. Poverty and financial constraints influence decisions on where and when to seek help for health complaints [11]. Financial barriers to surgical care can either be direct or indirect. Direct costs are those directly related to care, such as surgical fees, drugs and other medical supplies, transport to health facility and hospital stay. Indirect 
costs are accumulated as a result of the sickness or absence from work, with loss of income and productivity [9], both for the patient, and guardians and family supplying care in the hospital and at home after discharge.

In 2016 a cluster randomised national household survey was carried out using the Surgeons Overseas Assessment of Surgical need tool (SOSAS) to estimate the burden of untreated surgical disease in Malawi [14]. We found that $35 \%$ of the population were living with a condition that was in need of a surgical consultation or intervention and that $24 \%$ of reported deaths in the preceding 12 months could have been due to a surgical condition [14]. The purpose of this study was therefore to investigate and describe factors affecting access to health facilities for general medical and surgical care in Malawi, with special focus upon transport, finances and travel time.

\section{Methods \\ Setting}

Malawi has an estimated population of 18.4 million, with a GDP per capita of USD 300 (World Bank Group data base 2016). It is estimated that only $9 \%$ of health facilities have adequate staff to implement the WHO defined Essential Health Package (EHP) [9]. Malawi has 3 regions; The Northern, Central and Southern Regions. The Central and Southern regions are the most densely populated with 6.4 and 6.8 million respectively [14]. Malawi has 28 districts, of which one, Likoma, is an island in Lake Malawi. The country has a total of 48,233 registered settlements and the vast majority of these are in the rural areas. About $90 \%$ of the population live in rural areas and are dependent mostly on subsistence farming and small scale businesses [7].

\section{Study design}

This was a multi stage, clustered, probability sampling cross-sectional study, with systematic sampling of participants at the household level. The sample size was estimated at 1487 households based on a pilot study that was carried out in rural areas of the capital city, Lilongwe, in 2016 [14]. The sample size for the individuals was estimated at 2994 individuals $(95 \%$ CI) with a design effect of 1.5 at $25 \%$ prevalence of unmet surgical need in reference to the prior LMICs region reports [14-16].

The National Statistics Office provided a list of enumeration areas from the Malawi Census Board for 2008 national census records. There were 48,233 recorded settlements identified as potential enumeration areas. These settlements were randomised through computer generated random numbers, selecting 55 settlements as enumeration areas from each district in Malawi for this survey. Two or four households were systematically selected in each settlement depending on size. Two households were selected in a settlement with less than 10 households, while 4 households were selected in larger settlements. The systematic household selection was based on a floor bottle spin and selecting the third or fifth house in the direction of spin depending on the size of the settlement. Subsequently the bottle spinning was repeated after the household interview to select the next household in the new direction of the spin. The next fifth household was then picked if in a larger settlement or third household if in a smaller settlement, then repeating the process again to select the next household. Two household members were selected and interviewed per household, by first interviewing the head of the household, then selecting another member at random using random numbers based on number of members in the household. If this household member selected was a child (age below six years),mute or for some reason cannot speak, then the guardian was interviewed using the assent form on their behalf with permission granted by them. The total number of included households was 1479, with a total of 2958 people interviewed [14]. The study started out with 1486 households. Two heads of households refused to participate and for 5 households there were no data.

\section{Survey instrument}

The Surgeons Overseas Assessment of Surgical need tool (SOSAS) was used to collect data [14-16], and. This is a questionnaire based tool with three components. The first component outlines the general house-hold information i.e. Household size, type, gender and age distribution and demographics i.e. location (urban, rural or slum). The second and third part focused on the different modes of transportation they used in the past 12 months to travel with a sick or injured household member from home to the nearest health facility, to the district hospital and to a tertiary centre, occupation of participants etc. The time taken to reach the health facility was also recorded. Inquiry on the source and availability of money by the household head to reach the health facility in the last visit was done. It also had inquiries on the assumed cost of transport (Local currency) to reach these three levels of health care, and on the different reasons that contributed to the individuals not going to the health facility in time. These were based on household level, as reported by the head of the household.

The questionnaire was installed on 17 tablet computers (iPad 2, Apple Inc.), using File Maker Pro 12.0v3 (File maker inc., USA) software for data collection in English.

\section{Data collection}

Data collection was done by medical students trained at the end of their third year of academic training. They all 
underwent five days of training on how to use the questionnaire and computer tablet. A pilot study was carried out in Lilongwe prior to roll out of the main study in April 2016, to test the survey tool. Training was done prior to this pilot study and as a refresher after the pilot study in preparation for the national survey [14].

There were 32 trained data collectors, 14 female and 18 male. The period for data collection was from 1st July to 30th August 2016, during the main holiday for the medical students who did the data collection. Data collection was spilt into 2 phases. The first phase involved half of the data collectors covering all identified enumeration sites in the northern part of the Central Region and the whole of Northern Region. The second phase involved coverage of the rest of Central region and the Southern Region. In some of the enumeration areas people belonged to smaller population groups with unique languages or dialects. In these cases local translators were hired to secure good communication between the interviewer and the household member [14].

Each data collector covered approximately 4 households per day, therefore 60-64 households were interviewed every day. Interviews were done in the interviewees private homes. The collected data was merged and exported from the tablets into an Excel (Microsoft 2010) data base at the end of each day. Data was checked and exported directly into the pooled data base on a computer saver at the end of each of day, for data security and to assure the quality of the data collection [14]. Data backup was saved in cloud storage using wireless internet connection.

\section{Statistical analysis}

Data analysis was done using SPSS version 24. Univariate and multivariate statistical analysis was done for descriptive, relative frequencies and percentages as presented in the tables.

Pearson chi square test was used to compare the availability of financial resources between males and females for travel to access surgical health care at different levels of health care provision.

\section{Results}

Analysis performed on 1479 households revealed that $90.1 \%$ of the study population was located in rural areas (Table 1). The most common occupation among the participants was subsistence farming (40\%). $24.9 \%$ of the population reported not to be formally employed by an organisation i.e. non skilled and not on a payroll by government or non-governmental organisation for monthly salary (Table 1). Home makers i.e. those who are hired on short term contracts or piece works for a few days to weeks for construction of infrastructure represented $8 \%$, while domestic workers i.e. those who are hired to clean
Table 1 Demographics and household information

\begin{tabular}{|c|c|c|}
\hline & Frequency & $(\%)$ \\
\hline \multicolumn{3}{|l|}{ House hold data } \\
\hline \multicolumn{3}{|l|}{ Location } \\
\hline Rural & 1332 & 90.1 \\
\hline Urban & 107 & 7.2 \\
\hline Slum & 13 & 0.9 \\
\hline Not stated & 27 & 1.8 \\
\hline Median household size (range) & $6(1-47)$ & \\
\hline Total households & 1479 & \\
\hline Individual data (Employable age group 15-66 years) & 2448 & \\
\hline \multicolumn{3}{|l|}{ Sex distribution } \\
\hline Male & 977 & 39.9 \\
\hline Females & 1465 & 59.8 \\
\hline Not stated & 6 & 0.3 \\
\hline Median age, years (range) & $34(15-66)$ & \\
\hline \multicolumn{3}{|l|}{ Occupation } \\
\hline Farmer & 979 & 40.0 \\
\hline Unemployed (non-skilled/no salary) & 610 & 24.9 \\
\hline Own business & 437 & 17.9 \\
\hline Home maker (house Builder) & 196 & 8.0 \\
\hline Non-Government employee & 95 & 3.9 \\
\hline Government employee & 67 & 2.7 \\
\hline Domestic helper (House maid) & 47 & 1.9 \\
\hline Not stated & 17 & \\
\hline Total number of people surveyed & 2448 & 0.7 \\
\hline
\end{tabular}

homes and take care of young children in the homes represented $1.9 \%$ (Table 1 ).

It was reported by the household head that the most commonly reported mode of transport from home to the primary health facility was animal pulled carts $(44.8 \%)$ while travel to secondary level and tertiary level health facility was by public transport inclusive of public hospital ambulances (31.5 and $43.4 \%$ respectively) (Table 2). About a fifth (19.1 and 19.7\%) of the respondents would have to travel to their health centre or local hospital by using multiple means of transportation, with only $9.5 \%$ of using multiple modes to travel to a central hospital (Table 2). This may, for example, involve walking on foot to a certain place, hiring a push bicycle and possibly end up in a minibus or on the back of a lorry to the health facility.

Regardless of mode of transportation, it took a median of $1 \mathrm{~h}$ to travel to the nearest health centre, $1.5 \mathrm{~h}$ to travel to district hospital and $2.5 \mathrm{~h}$ to travel to the nearest central hospital respectively.

Of the people interviewed, significantly more women than men denied having money for transport to visit health centre, district hospital and central hospital as 
Table 2 Transport mode to health facility for 1479 households

\begin{tabular}{llll}
\hline Mode of transport & Health centre & District hospital & Central hospital \\
\hline & $\mathrm{N}(\%)$ & $\mathrm{N}(\%)$ & $\mathrm{N}(\%)$ \\
Public transport/ambulance & $50(3.4)$ & $466(31.5)$ & $642(43.4)$ \\
Private hire & $17(1.1)$ & $153(10.3)$ & $165(11.2)$ \\
Motorcycle & $26(1.8)$ & $34(2.3)$ & $2(0.1)$ \\
Bicycle & $153(10.3)$ & $125(8.4)$ & $17(1.1)$ \\
Boat & $2(0.1)$ & $2(0.1)$ & - \\
Animal (Ox) cart & $663(44.8)$ & $216(14.6)$ & $12(0.8)$ \\
Walking on foot only & $26(1.8)$ & $11(0.7)$ & $9(0.6)$ \\
Multiple (Combined) & $283(19.1)$ & $292(19.7)$ & $140(9.5)$ \\
Not stated & $285(19.3)$ & $180(12.2)$ & $492(33.3)$
\end{tabular}

$n=1479$ Households

* responses from household members in reply to the question: "What is the main way for you or your household members to go to a secondary health facility?"

reported by the household head (Table 3). For the household heads; $54 \%$ male and $41.6 \%$ female respondents reported to have money available to go to their local health centre, $52.8 \%$ males and $43.9 \%$ females \% to district hospital and $54.5 \%$ males and $41.7 \%$ females to central hospital respectively (Table 3 ). At the overall household interview with family heads, less women than men stated that they had financial resources to access healthcare $(p<0.001)$.

Of the interviewed households heads; 56.3 and $27 \%$ would have to spend less than 1 US\$ to travel to their health centre, and district hospital whereas $9.5 \%$ would spend less than 1 US\$ to go to their central hospital. (Table 4). Travel to central hospital would cost up to US\$ 7 in $20.6 \%$ of the respondents and only $1.1 \%$ of the same amount to travel to a health centre.

\section{Discussion}

This study confirmed the cost of and access to transport as significant barriers to accessing timely health care by rural communities in Malawi. Almost half of the respondents had financial constraints influencing their access to health care for surgical conditions. Inadequate road infrastructure, finances, ambulance services and expensive private transport all play a role as transportation barriers to access a health facility. This is in line with findings from another Malawian study by Abiiro et al. that people from rural areas spend more time travelling than those in urban regions, and that lack of transport, inadequate financial resources and poor road conditions limit the possibilities of people in rural communities to access health facilities [17].

Other reviews on the barriers to surgical health care encountered by patients in rural sub-Saharan Africa have identified cultural, structural, and financial constraints as barriers and concluded that patient and community education and transport needs should be made available $[4,18]$. Punchak et al. reported in-adequacy in neurosurgical service in sub-Saharan Africa. The average percentage of the population with access to neuro surgery within $2 \mathrm{~h}$ window was shown to be $25.26 \%$ in sub-Saharan Africa, while is was $93.3 \%$ in Eastern Europe and Central Asia. This was attributed to low numbers of neurosurgery providers, equipment challenges and unreliable access to transportation to neurosurgical centres in Low- and middle income countries, including the sub-Saharan region [19].

In general, district hospitals provide less surgical care than central hospitals. Galukande et al. reported relatively low rates of major surgery at district hospitals in Eastern Africa, ranging from 50 to 450 surgical procedures per 100,000 population [18]. More than $95 \%$ of

Table 3 Availability of money for transportation to health care facility for 1479 households

\begin{tabular}{|c|c|c|c|c|c|c|c|c|c|}
\hline & \multicolumn{3}{|c|}{ Local health centre } & \multicolumn{3}{|c|}{ District hospital } & \multicolumn{3}{|c|}{ Central hospital } \\
\hline & $\begin{array}{l}\text { Male } \\
\text { Head }\end{array}$ & $\begin{array}{l}\text { Female } \\
\text { Head }\end{array}$ & $\begin{array}{l}\text { Not } \\
\text { stated }\end{array}$ & $\begin{array}{l}\text { Male } \\
\text { Head }\end{array}$ & $\begin{array}{l}\text { Female } \\
\text { Head }\end{array}$ & $\begin{array}{l}\text { Not } \\
\text { stated }\end{array}$ & $\begin{array}{l}\text { Male } \\
\text { Head }\end{array}$ & $\begin{array}{l}\text { Female } \\
\text { Head }\end{array}$ & $\begin{array}{l}\text { Not } \\
\text { stated }\end{array}$ \\
\hline Yes $(Y)$ & $135(54.0 \%)$ & $104(41.6 \%)$ & $11(4.4 \%)$ & $143(52.8 \%)$ & 119 (43.9\%) & $9(3.3 \%)$ & $85(54.5 \%)$ & $65(41.7 \%)$ & $6(3.8 \%)$ \\
\hline No $(N)$ & $185(36.2 \%)$ & $296(57.9 \%)$ & $30(5.9 \%)$ & 277 (38.8\%) & $394(55.3 \%)$ & $42(5.9 \%)$ & $214(37.8 \%)$ & $315(55.7 \%)$ & $37(6.5 \%)$ \\
\hline Not stated & $315(43.9 \%)$ & $362(50.4 \%)$ & $41(5.7 \%)$ & $215(43.4 \%)$ & 249 (50.3\%) & $31(6.3 \%)$ & $336(44.4 \%)$ & $382(50.5 \%)$ & 39 (5.2\%) \\
\hline Chi-sq M/F: & $\mathrm{Y} / \mathrm{N}$ & $p<0,001$ & & & $p<0,001$ & & & $p<0,001$ & \\
\hline
\end{tabular}

* as judged by the senior household member/household head interviewed in reply to the question: "...Are you always able to provide these means for transport of a sick household member......?" 
Table 4 Cost to reach health facility in 1479 households

\begin{tabular}{|c|c|c|c|c|c|c|}
\hline & \multirow{2}{*}{$\begin{array}{l}\text { Health Centre } \\
\mathrm{N}\end{array}$} & \multirow{2}{*}{$\begin{array}{l}\text { District hospital } \\
\%\end{array}$} & \multicolumn{4}{|c|}{ Central hospital } \\
\hline & & & $\bar{N}$ & $\%$ & $\mathrm{~N}$ & $\%$ \\
\hline US\$ 0.00-0.99 & 832 & 56.3 & 399 & 27.0 & 141 & 9.5 \\
\hline US\$1.00-1.50 & 135 & 9.1 & 292 & 19.7 & 73 & 4.9 \\
\hline US\$ 1.51-3.50 & 63 & 4.3 & 285 & 19.3 & 161 & 10.9 \\
\hline US\$ $3.51-7.00$ & 16 & 1.1 & 159 & 10.8 & 305 & 20.6 \\
\hline US\$ 7.01-13.50 & 5 & 0.3 & 32 & 2.2 & 153 & 10.3 \\
\hline US\$ 13.51-25.00 & & & 17 & 1.0 & 38 & 2.6 \\
\hline Not stated & 428 & 28.9 & 295 & 19.9 & 608 & 41.1 \\
\hline
\end{tabular}

US\$ $1.00=$ Mk 740

Malawi GDP per capita is US\$300

* as estimated by the person interviewed in reply to the question: "What does

it cost you to provide transportation to a tertiary health facility for a sick

household member?........."

the population in South Asia and Central, Eastern and Western sub-Saharan Africa do not have access to surgical care, whereas less than $5 \%$ of the population in Australia, high-income America and Western Europe lack access [21]. This demonstrates the unmet surgical need and confirms the barriers to access to essential surgery in rural districts in sub-Saharan Africa [20].

$50 \%$ of the Malawi population live within five kilometres from their health centre, a walkable distance for a healthy person, though not necessarily for someone seeking health care $[9,10]$. Accordingly, it is surprising that only $1.8 \%$ of the respondents stated that travel on foot was the main way for their household members to go to a primary health facility, reflecting mostly the use of bicycles and Ox-carts for travelling short distances.Secondary level and tertiary level health facilities, however, are often far from people's homes. District hospitals support health centres with ambulance services to ferry sick people from the health centre to the district hospital, and on to the tertiary central hospitals if needed. This hospital ambulance transport support system usually gives priority to maternity patients, especially urgent obstetric complications. Each district hospital has a minimum of 15 health centres to support within its catchment area, and may have only 2 or 3 ambulances. Unfortunately, these may also be off the road due to lack of fuel or vehicle spare parts, and they often fail to go to health centres to fetch patients.

Eventually, communities have to find alternative transportation from home to the health centre, and also from the health centre to a district hospital. Elderly people may carry children on their back over considerable distances just to seek surgical health care. Sometimes when they get to a health centre, they are informed that the facility does not have resources for surgical treatment e.g. sutures for closing wounds or plaster of Paris (POP) for treating fractures, hence they have to wait for an ambulance coming for obstetric emergency patient to come and collect them together to go to the district hospital. Otherwise they should be prepared to find and pay for alternative means of transportation to travel to the district hospital. This time consuming activity contributes to the delay in presentation to health facility as another barrier.

Central hospitals offer tertiary surgical services for emergency and elective conditions, but are located in the big cities far from most rural areas. These central hospitals serve as both secondary and tertiary level facilities due to inadequate surgical services at the secondary level. Sometimes resources are so limited that health service seekers have to bypass the district hospitals and travel directly to the central hospital in order to be assisted accordingly. When patients get to a district hospital, they get referred to a central hospital, and usually the mode of transport is by public hospital ambulance which sometimes delays time of travel because they have to wait to fill it up with more patients, hence posing as another barrier.

Government public transportation is not available in most rural areas either due to poor road infrastructure or unavailability of public transport supported by government. This has led to private owned sources of transport which are also very costly. This private mode of transportation varies from ox-cart, push bicycle, motorcycles, and motor-tricycles to big lorries, minibuses and buses. Depending on availability of funds, and unpredictability of availability of ambulance services, the only way is to hire an ox-cart, push bicycle or any other mode of transportation to ferry them to hospital. Though it costs less than USD 1 to travel to a health centre, the needed financial resources are often not readily available. About $56 \%$ of the population reported to have an equivalent of 1 USD to enable them to travel to a health centre.

White et al. [22] had similar findings of cost of travel to centres that provide surgical care and have recommended that NGOs and other stake holders should be involved in LMICs provision of surgical care by actively engaging in case finding and offer surgical services [22]. This should be done by travelling to the rural location to provide surgical care rather than expecting the patients to travel to access care [23]. This could be achieved by designing surgical camps in the district and upscaling surgical services at district hospital level.

The transport barriers described in this study contribute significantly to inadequate access to general medical and surgical services in Malawi such that the burden of disease is still unacceptalby large, with as many as $35 \%$ of the population living with a condition needing a surgical consultation or treatment (Varela et al) [14]. Though human and other resources contribute to this burden, transport availability between health centres and district hospitals and between district hospital and 
central hospital also needs to be emphasised in order to improve health for all Malawians, especially surgical health care as a non-communicable disease section of the essential package.

One of the limitations to this study was that the transport limitation was not assessed according to seasonal availability of funds in the communities. In Malawi, during harvest time of farm produce, the availability of money is better than during the field preparation and growing season for example. This study was done during the time farmers were busy preparing their fields for the upcoming growing season. This could be associated with low availability of funds to support transport to hospital because priority is on farm inputs like seed and fertiliser for the farms. Another limitation was that the cost of mode of transport was not estimated in reference to the type of transport used. For example the cost of ox-cart was not easily compared to cost of push bicycle or car because the cost of transportation is based on the distance travelled not the vessel used. Cars and buses are generally more expensive that the other modes of transportation though not readily available. One weakness of using the tool for data collection was that this was based on interviews and hence has a recollection and recall bias may have influenced the results. Also, the information was self-reported and lacked objective measures. Missing information in many reported variables is in general a major concern, although there is no reason to believe that this has introduced a selection bias. The strengths of this study are the size, systematic selection of households and participants, use of a standardized instrument, use of trained personnel and high response rate.

\section{Conclusion}

In Malawi, lack of suitable transport, lack of finances and prolonged travel time to tertiary health facilities, all pose barriers to timely access of health care. Improving the availability of free transport for patients between rural health centres and district hospitals, and between the district and central hospitals, could help overcome some of the most pronounced barriers to surgical health care experienced by people in rural Malawi.

\section{Abbreviations \\ CHAM: Christian Health Association of Malawi; Cl: Confidence Interval; DALYs: Disability Adjusted Life years; EPH: Essential health Package; GDP: Gross Domestic Product; LIC: Low Income countries; LMIC: Low and Middle Income countries; NGO: Non-Government Organisations; NORAD: Norwegian Agency for Development; NORHED: Norwegian Programme for Capacity Development in Higher Education and Research for Development; POP: Plaster of Paris; SOSAS: Surgeons Overseas Assessment of Surgical need; SPSS: Statistical Package for Social Scientists; USD: United States Dollar; WHO: World Health Organisation}

\section{Acknowledgements}

The authors would like to thank Bente Moen, professor at University of Bergen, Centre for International health for her help with a significant revision and editing of this manuscript.
The authors would also like to thank the data collectors: Manduwa Saka, Wongani Mumba, Blessings Phakati, Lovemore Malunga, peter Jere, Annie Chimaimba, Loviisa Mulanje, Samuel Mpinganjira, Mercy Josaya, Watipaso Mkhuta, Patricia Muwanya, Andrew Malanga, Henry Mwakalinga, Trasizio January, Dickson Hangiwa, Timothy Mutafya, Dan Msamanyada, Denis Chauma, Agatha Mlenga, Prince Goliati, Moses Msukuma, John Phalula. Without their hard and dedicated work over two months in 2016, this study would not have been possible.

All the above acknowledged persons consented to the publication of this manuscript.

\section{Funding}

Permission to use the SOSAS tool was granted at no cost by Surgeons Overseas. The Norwegian Agency for Development Cooperation (NORAD) financed a "Norhed" programme supporting the training of surgeons and surgical research in Malawi. This programme provided a PhD grant to authors CGV and LNB, payed for cost of the data collection exercise and financed the computer tablets for data collection. The computer tablets were donated to the Kamuzu Central Hospital surgery department for further surgical research at the end of the study. The Norhed programme also covered costs in relation to data collectors support for meals, transport costs and accommodation during the data collection period.

\section{Availability of data and materials}

The datasets used and analysed during the current study are available from the corresponding authors on reasonable request.

\section{Authors' contributions}

CGV: project idea, planning \& implementation, data collection, first manuscript draft and revisions.

SV: project idea and planning, supervision, data interpretation, manuscript revisions.

NM: supervising, data interpretation, manuscript revisions. RG: supervision, data interpretation, manuscript revisions.

LNB: data collection, manuscript revisions.

$\mathrm{AV}$ : project idea and planning, supervision, manuscript revisions, assisted with data analysis and interpretation.

All authors approved the manuscript, its results and consented for publication of the article.

\section{Ethics approval and consent to participate}

The research was approved by the College of Medicine Research Ethics Committee (P03/15/1696), and Norwegian Regional Research ethics committee (2016/1392/REK Vest). Consent (for the adults) and assent (for the minors and mute persons) forms were designed and translated into the local languages. These were used to seek informed consent prior to conducting the interviews.

\section{Consent for publication}

This was not applicable.

\section{Competing interests}

There are no competing interests available from all authors.

\section{Publisher's Note}

Springer Nature remains neutral with regard to jurisdictional claims in published maps and institutional affiliations.

\footnotetext{
Author details

${ }^{1}$ Department of Surgery Kamuzu Central Hospital, Lilongwe, Malawi. ${ }^{2}$ University of Malawi, College of Medicine, Lilongwe, Malawi. ${ }^{3}$ Department of Clinical Medicine and Centre for International Health, University of Bergen, Bergen, Norway. ${ }^{4}$ Department of Orthopaedic Surgery, Haukeland University Hospital, Bergen, Norway. ${ }^{5}$ Department of Research \& Development, Haukeland University Hospital, Bergen, Norway. ${ }^{6}$ Department of Gynecology and Obstetrics, Johns Hopkins Medicine, Baltimore, USA. ${ }^{7}$ Department of Obstetrics and Gynecology, Alaska Native Medical Centre, Anchorage, USA. ${ }^{8}$ Department of Surgery, Queen Elizabeth Central Hospital, University of Malawi, College of Medicine, Blantyre, Malawi.
} 
Received: 24 August 2018 Accepted: 21 February 2019

Published online: 05 March 2019

\section{References}

1. Shrime MG, Bickler SW, Alkire BC, Mock C. Global burden of surgical disease: an estimation from the provider perspective. Lancet Glob Health. 2015; 3(Suppl 2):S8-9. https://doi.org/10.1016/\$2214-109X(14)70384-5.

2. Nordberg E. (2000) injuries as a public health problem in sub-Saharan Africa: epidemiology and prospects for control. East Afr Med J. 2000;77(12 Suppl): S1-43.

3. Taira BR, McQueen KAK. Burkle FM (2009) burden of surgical disease: does the literature reflect the scope of the international crisis? World J Surg. 2009:33(5):893-8. https://doi.org/10.1007/s00268-009-9981-x.

4. Premkumar A, Ying X, Mack Hardaker W, Massawe HH, Mshahaba DJ, Mandari F, Pallangyo A, Temu R, Masenga G, Spiegel DA, Sheth NP. Access to Orthopaedic surgical Care in Northern Tanzania: a modelling study. World J Surg. 2018. https://doi.org/10.1007/s00268-018-4630-x.

5. Lin BM, White M, Glover A, Wamah GP, Trotti DL, Randall K, Alkire BC, Cheney ML, Parker G, Shrime MG. Barriers to surgical care and health outcomes: a prospective study on the relation between wealth, sex, and postoperative complications in the republic of Congo. World J Surg. 2017; (1):14-23. https://doi.org/10.1007/s00268-016-3676-x.

6. Grimes CE, Law RSL, Borgstein ES, Mkandawire NC, Lavy CBD. Systematic review of met and unmet need of surgical disease in rural sub-Saharan Africa. World J Surg. 2012;36(1):8-23. https://doi.org/10.1007/s00268-0111330-1.

7. Makaula P, Bloch P, Banda HT, Mbera GB, Mangani C, de Sousa A, Nkhono E, Jemu S, Muula AS. Primary health care in rural Malawi - a qualitative assessment exploring the relevance of the community-directed interventions approach. BMC Health Serv Res. 2012;12:328. https://doi.org/ 10.1186/1472-6963-12-328.

8. Eide AH, Mannan H, Khogali M, van Rooy G, Swartz L, Munthali A, Hem K-G, MacLachlan M, Dyrstad K. Perceived Barriers for Accessing Health Services among Individuals with Disability in Four African Countries. PLoS One. 2015. https://doi.org/10.1371/journal.pone.0125915.

9. Geoffroy E, Harries AD, Bissell K, Schell E, Bvumbwe A, Tayler-Smith K, Kizito W. Bringing care to the community: expanding access to health care in rural Malawi through mobile health clinic. PHA. 2014;4(4):252-8. https://doi. org/10.5588/pha.14.0064.

10. Richard Record and Abdu Mohiddin. An economic perspective on Malawi's medical "brain drain" Glob Health 2006, 2:12 doi: https://doi.org/10.1186/ 1744-8603-2-12.

11. Lungu K, Kamfosa V, Hussein J, Ashwood-Smith H. Are bicycle ambulances and community transport plans effective in strengthening obstetric referral systems in southern Malawi. Malawi Med J. 2001.

12. Munthali AC, Mannan H, MacLachlan M, Swartz L, Makupe CM, Chilimampunga C. Non-use of formal health Services in Malawi: perceptions from non-users. Malawi Med J. 2014:26(4):126-32.

13. Govender RD. The barriers and challenges to health promotion in Africa. $S$ Afr Fam Pract. 2005;47(10):39-42. https://doi.org/10.1080/20786204.2005. 10873303.

14. Varela C, Young S, Groen R, Banza L, Mkandawire NC, Viste A. Untreated surgical conditions in Malawi: a randomised cross-sectional nationwide household survey. Malawi Med J. 2017;29(3):231-6. https://doi.org/10.4314/ mmj.v29i3.1.

15. Groen RS, Samai M, Stewart KA, Cassidy LD, Kamara TB, Yambasu SE, et al. Untreated surgical conditions in Sierra Leone: a cluster randomized, crosssectional countrywide survey, Lancet 2012; 380 (9847): 1082-1087. doi: https://doi.org/10.1016/S0140-6736(12)61081-2. Epub 2012 Aug 14.

16. Groen RS, Samai M, PetrozeRT, Kamara TB, Yambasu SE, CallandJF, et al. Pilot testing of a population-based surgical survey tool in Sierra Leone. World J Surg 2012, Apr; 36 (4): 771-774. Doi: https://doi.org/10.1007/s00268-0121448-9.

17. Gilbert Abotisem Abiiro, Grace Bongololo Mbera, Manuela De Allegri. Gaps in universal health coverage in Malawi: A qualitative study in rural communities. BMC Health Serv Res 2014, 14:234 doi: https://doi.org/10. 1186/1472-6563-14-234.

18. Moses Galukande, Johan von Schreeb, Andreas Wladis, Naboth Mbembati, Helder de Miranda, Margaret E. Kruk, Sam Luboga, Alphonsus Matovu, Colin McCord, S. Khady Ndao-Brumblay, Doruk Ozgediz, Peter C. Rockers, Ana Roma'n Quin ones, Fernando Vaz, Haile T. Debas, Sarah B. Macfarlane.
Essential Surgery at the District Hospital: A Retrospective Descriptive Analysis in Three African Countries. March 2010 | Volume 7 | Issue 3 | e1000243.

19. Maria Punchak, Swagoto Mukhopadhyay, Sonal Sachdev, Ya-Ching Hung, Sophie Peeters, Abbas Rattani, Michael Dewan, Walter D. Johnson, Kee B Park. Neurosurgical Care: Availability and Access in Low-Income and MiddleIncome Countries. WORLD NEUROSURGERY. https://doi.org/10.1016/j.wneu. 2018.01.029.

20. Grimes CE, Bowman KG, Dodgion CM, et al. Systematic review of barriers to surgical care in low-income and middle income countries. World J Surg. 2011;35:941. https://doi.org/10.1007/s00268-011-1010-1.

21. Alkire BC, Raykar NP, Shrime MG, Weiser TG, Bickler SW, Rose JA, Nutt CT, Greenberg SLM, Kotagal M, Riesel JN, Esquivel M, Uribe-Leitz T, Molina G, Roy N, Meara JG, Farmer PE. Global access to surgical care: a modelling study. Lancet Glob Health. 2015 Jun;3(6):e316-23. https://doi.org/10.1016/ S2214-109X(15)70115-4.

22. White MC, Hamer M, Biddell J, Claus N, Randall K, Alcorn D, Parker G, Shrime MG. Facilitating access to surgical care through a decentralised case-finding strategy: experience in Madagascar. BMJ Glob Health. 2017;2:e000427. https://doi.org/10.1136/bmjgh-2017-000427.

23. Shrime MG, Hamer M, Mukhopadhyay S, Kunz LM, Claus NH, Randall K, Jean-Baptiste JH, Maevatombo PH, Toh MPS, Biddell JR, Bos R, White M. Effect of removing the barrier of transportation costs on surgical utilisation in Guinea, Madagascar and the republic of Congo. BMJ Glob Health. 2017;2: e000434. https://doi.org/10.1136/bmjgh-2017-000434.
Ready to submit your research? Choose BMC and benefit from:

- fast, convenient online submission

- thorough peer review by experienced researchers in your field

- rapid publication on acceptance

- support for research data, including large and complex data types

- gold Open Access which fosters wider collaboration and increased citations

- maximum visibility for your research: over $100 \mathrm{M}$ website views per year

At BMC, research is always in progress.

Learn more biomedcentral.com/submissions 